\title{
On-Line Bibliographic System Instruction
}

\author{
TRUDI BELLARDO, GAIL KENNEDY, AND \\ GRETCHEN TREMOULET
}

A course in on-line bibliographic systems was introduced into the curriculum of the College of Library Science at the University of Kentucky. It was taught in five-week sections by three instructors who were practicing librarians and each an expert in one type of bibliographic network: OCLC, MEDLINE, or Lockheed DIALOG. Library space, equipment, and materials were utilized.

The over-all goals of the course were to develop terminal skills and related proficiencies and to instill a knowledge of the administrative considerations relative to various kinds of networks. Despite problems encountered related to class size, scheduling, theft of equipment, and supplementary readings, the students evaluated the course highly and the instructors felt it was an over-all success and worth repeating.

WITH THE widespread availability of on-line bibliographic systems (e.g., ORBIT, DIALOG, OCLC, MEDLINE, etc.), and in recognition of the fact that such systems have clearly become a permanent part of the library profession, graduate programs of library education are currently trying to decide how instruction relating to such systems can be most efficiently and effectively introduced into the curriculum.

A number of different patterns for offering on-line instruction are available to the library educator, and a state-of-the-art survey of practice among library programs accredited by the American Library Association has recently been published by S. P. Harter. ${ }^{1}$ The approach taken at the University of Kentucky College of Library Science is sufficiently different from those taken at other institutions to suggest that a discussion of this experience might be helpful to others introducing such an instructional

Bellardo is Data Services Librarian, Kennedy is Acquisitions Librarian, both at the M. I. King Library, and Tremoulet is Search Analyst, Medical Center Library and Communication System, all at the University of Kentucky, Lexington, KY 40506. 
component to their program of library education.

Program Structure. Through 1975 student exposure to on-line bibliographic systems at the College of Library Science was essentially limited to classes which emphasized the conceptual-theoretical issues of computerbased information storage and retrieval. These classes were supplemented by system demonstrations which were provided by various elements of the University of Kentucky Libraries and the Medical Center Library. The primary goal of such instruction was to provide the students with a conceptual understanding of the systems and to develop what A. Kent refers to as system "literacy." ${ }^{2}$ It soon became apparent that this approach to on-line instruction was inadequate to the professional needs of the students. While the conceptual aspects of information storage and retrieval were adequately treated within the structure of a number of courses ranging from cataloging and classification to information storage and retrieval, the experiential or practical aspects of system operation were being given considerably less attention. In short, the students understood the structural nature of on-line systems but did not understand operational aspects or procedures.

The first step in expanding the on-line instructional program took the form of providing students with an opportunity for "hands-on" experience with ORBIT and DIALOG through an existing course entitled Information Storage and Retrieval Systems. The instructional component was designed jointly by the instructor of the course and the data services librarian at King Library. The experiential portion of the course was taught by the data services librarian and while it was judged a valuable unit of the course by the students, it was agreed that the approach fell short of providing students with a desired level of "operational functionality." ${ }^{3}$

In order to improve the students' operational performance it was decided to further expand the program during the 1977 spring semester by introducing a completely separate course called Computer-Based Bibliographic Networks. The course was designed to provide students with exposure to a range of existing on-line systems and consisted of three distinct instructional units; one unit devoted to a cooperative library network (OCLC), another to a subject-specific system (MEDLINE) and a third to a multiple-database system which would have application in general reference (DIALOG). While the course was to emphasize experiential learning, it was expected that the instructors would consider a number of administrative and operational issues related to the provision of on-line bibliographic services and computer-based information storage and retrieval as well.

In implementing the course the College of Library Science had essentially two alternative approaches which it could take: (1) It could develop 
an independent capability within the college, requiring it to acquire qualified instructors, necessary hardware and facilities; or (2) It could rely upon instructors and facilities already existing within the university library system. Given the experiential nature of the intended course, the existence of qualified and experienced professional librarians who were willing to serve as instructors, and the relatively high cost of developing an independent capability, it was decided that the most cost-effective approach would be to build on existing staff and facilities.

The professional librarians selected as instructors for the course each had extensive experience with one of the three on-line bibliographic systems included in the course. The MEDLINE and DIALOG instructors were full-time search analysts, and the OCLC instructor had been instrumental in implementing OCLC in the university library system and had supervised the on-line cataloging section for two years.

The three-hour class was scheduled for one evening each week, taking advantage of the reduced rates available from MEDLINE and DIALOG and avoiding competition with normal library use of the available terminals. The students were divided into three groups of approximately 12 students each; each group studied one of the systems for five weeks and then rotated to another system.

A number of questions arose relative to the scope and complexity of the three separate sections. How much could the students absorb in each of the three short courses? What kinds of background and preparation would they - should they - bring to each section? Would their absorption level increase as they rotated from one section to another or would they suffer learning interference and confusion? From a survey of the students who enrolled in the course it was learned that virtually all had previously taken an introductory cataloging-classification course (the only prerequisite for the course); 17 per cent had taken, or were in the process of taking, one or more advanced cataloging courses; 69 per cent had taken a course in information science; 17 per cent were taking concurrently a course in information storage and retrieval systems, and 17 per cent had previously enrolled in a course dealing with library automation. Two of the students had some training on OCLC. In actuality this statistical data provided little help in answering the above questions, and the instructors had to be sensitive to cues from the students as the course progressed and to modify the pace and content of the course accordingly.

The syllabus for the course was actually three individual syllabi compiled independently by the instructors and then coordinated in order to ensure a degree of consistency and uniformity in style. The instructors agreed to give a written examination at the end of each five-week session and the final grade of a student represented a combination of the student's grades received in each of the individual units. 
Each of the individual instructional units is discussed in the following sections. This discussion is followed by an over-all summary which highlights the major problems encountered in teaching the course and changes which have been made in the program as a result of this experience.

DIALOG Instructional Unit. The DIALOG system was chosen for training on-line bibliographic retrieval in general reference largely because its command language, unlike that of ORBIT, is very different from MEDLINE, and also because of the availability of C. P. Bourne's DIALOG Lab Workbook, which guided the "hands-on" work. The workbook was really too long and detailed for the five-week course but proved helpful nonetheless. ${ }^{4}$ The DIALOG retrieval system provides access to almost 60 databases (as of July, 1977) but only six were available with Lockheed's classroom instruction program and Bourne's workbook concentrated on the ERIC database.

The three original objectives of the DIALOG section were: to develop skills in on-line procedures and protocols; to develop skills in question negotiation and search strategy formulation; to provide an overview and history of the database industry, library administration of on-line reference services, and key concepts in automated information storage and retrieval. The first objective was realized through on-line sessions during which each of the ten to twelve students present took a turn at the terminal to work through a few of the exercises at the end of the chapters in Bourne's workbook while the rest of the students watched. The students complained initially of being self-conscious in front of their classmates, but most of them gained confidence as the course progressed. This method was awkward in some respects, but it was the instructor's solution to the large class size, too few terminals, and the limited amount of searching funds. In addition, it enabled the class to cover many more exercises and to observe more on-line techniques than if the time had been divided up into short sessions with only a few students present. The instructor also spent an hour with each group demonstrating the other on-line systems available at the University of Kentucky. The demonstrations were done at the end of each five-week session, after the students were very familiar with DIALOG. Consequently they were much more perceptive to the points of comparison among the systems than a group that had had no previous training would have been.

The second objective of the section was only partially realized because of lack of time. A few class discussions covered search design, but negotiation skills and variations in search tactics were not explored very deeply.

The third objective was achieved largely through class discussions, outside readings and a glossary of initialisms and retrieval jargon prepared by the instructor. The most helpful items on the reading list were $\mathrm{D}$. 
M. Wax, A Handbook for the Introduction of On-line Bibliographic Search Services Into Academic Libraries and R. W. Christian, The Electronic Library: Bibliographic Data Bases 1975-76. ${ }^{5}$

A fourth objective, which evolved from the class discussions, was to increase the students' awareness of the current controversial issues that are being debated at conferences and in the literature. These topics included charging for on-line services, "price wars" and other kinds of competition among database vendors, the need for standards and standardization, the proper role of the federal government, etc.

In spite of the emphasis in class on achievement of the first objective, the students were graded mainly on the written test rather than on terminal skills or class participation. Without clear performance standards established in advance, it proved extremely difficult to assess these aspects fairly. In the future, fair performance criteria and evaluation measures need to be established that will help both student and teacher.

The instructor felt that the section was most valuable for those students who had taken other information science courses, and would recommend that a course in information storage and retrieval systems be a prerequisite for this course. This is not likely to be implemented soon, but other changes that will likely be made the next time the course is taught include increasing the importance of on-line performance as a grading factor; breaking the section into two groups, with each group spending shorter but more intensive terminal sessions; using videotape for analysis of the pre-search interview; and revamping the reading list to add a broader range of viewpoints on controversial issues.

OCLC Instructional Unit. The OCLC unit aimed at fulfilling a dual purpose. The first goal was to provide an introduction to cooperative automated library networking - history, purpose, and current status emphasizing OCLC, but covering other regional networks as well. Secondly, it was hoped that a series of on-line exercises would enable students to develop some skill in the use of the OCLC 100 terminal and familiarity with the OCLC database.

Class time during each of the five-week units was divided between discussion and on-line practice. An assigned group of readings covering a fairly broad spectrum of network activities provided the bases for class discussions. The class addressed such topics as the reasons networks began and flourished; the impact of networks on libraries' technical and public services; the effects of networks on interlibrary cooperation; products and services of networks; and relationship between OCLC and its affiliate networks. The discussions also included currently debated issues concerning network governance and administration, network system growth strategy, and libraries' utilization of emerging computer capabilities. 
Hardware and software of the OCLC system were examined at a basic, non-technical level. Since a beginning cataloging course was a prerequisite for this course, database records and their use for cataloging purposes could be covered in some depth.

On-line exercises concentrated on building skill in three major terminal operations: database searching; editing of bibliographic records; and inputting original cataloging. Self-Instructional Introduction to the OCLC Model-100 Terminal by B. Juergens was selected as an introductory text for terminal operation and searching. ${ }^{6}$ After an in-class demonstration students completed the exercises in Juergens' manual on their own.

For editing and inputting practice the SOLINET Terminal Training Manual, ${ }^{7}$ which combines audio cassettes and printed exercises, was used. On-line exercises were done independently by students in most cases. Problems and experiences were brought to class for discussion each week. The OCLC instructional videotapes produced at Kent State University were received late in the semester, in time for only the last unit. The latter two tapes of the four-tape series proved especially appropriate for the class in that they are designed for librarians and library science students and demonstrate some of the more complicated terminal operations.

In addition to terminal operations and discussions of topics relevant to networking, fixed and variable field tagging of records for input cataloging was also introduced. The final group of students went into tagging in some depth while the earlier groups received a more cursory introduction.

The test was given during the fifth class period for each group and was composed of short answer and essay questions covering the readings and class discussions along with a brief quiz on terminal operations.

Some problems and needed changes in the OCLC unit were obvious as the course progressed and others were brought to light by student observations. An unexpected development that became apparent after the first rotation and intensified in the third unit was that each progressive group was initially more advanced than the previous one. Because the students were grouped by random selection and there was no concentration of expertise in any one group, this phenomenon (which was observed by all instructors) was no doubt attributable to basic system similarities and terminology learned in the first unit for each group. As a result, each succeeding group required less basic instruction and could cover more material in five weeks. Adjustments in class structure and methodology were required with each unit. These adjustments should be no problem when anticipated but effort should be taken to minimize the difference in instruction given to consecutive groups in the same semester.

Flexible availability of the OCLC system and the library's terminals made possible out-of-class on-line practice assignments. The outside as- 
signments were initially made to purposefully free class meetings for group discussions intended to develop understanding of networks' goals and operations. However, these discussions wore thin when extended over three hour class periods. In addition, the reading list, which formed the base for discussion, was occasionally redundant and could have been pared down with no real loss of content. A balance of discussion and on-line practice during the class period seemed to be more palatable than the excessively long discussions. When this approach was adopted during the last unit, the productive atmosphere during group terminal practice was immediately apparent. The students learned from each other and enjoyed attacking more difficult procedures together.

MEDLINE Instructional Unit. Four objectives were identified for the MEDLINE section. The first was to develop familiarity with on-line searching procedures; the second, to develop ability to design search strategies, the third, to become acquainted with MeSH; and the last, to gain an overview of the use and usefulness of MEDLINE. Fulfillment of the first three was dependent largely on lecture material and terminal practice. The last was dependent upon the readings.

The content and structure of the unit was governed somewhat by the length and frequency of the class meetings. The five-week session was not long enough to cover both machine mechanics and vocabulary in great detail. A decision was made to emphasize machine mechanics (commands, format of entry, Boolean logic, etc.), since that was considered the primary objective of the unit. Thus the MeSH vocabulary, so important to the system, was introduced only to the extent that the students could understand the relation of the tree structure and subheadings to the alphabetic list.

The five class meetings were used for a lecture, on-line practice, and the test. The lecture, given during the first class meeting, introduced the alphabetic MeSH, the tree structure, MEDLINE, the backfiles, Boolean logic, some of the commands, and some techniques such as offsearch, offline printing, author searching, textword searching, etc. The lecture was heavily supported by transparencies. For the next three meetings the class was divided into four groups of three students each; each group had a 30-minute terminal session. The students were given search questions to have formulated by the time they arrived. These queries were designed to illustrate the techniques discussed in the lecture. On arrival they were given a "correct" formulation and each student executed a search while the other two watched. In addition they had some free time to practice various commands. The final examination covered both the lecture and reading assignments and consisted of short essay questions, search questions to formulate, and a long essay question. Grades were determined largely by test scores. 
The reading assignment consisted of several parts. Nine journal articles were included which aimed largely at the extent of use of MEDLINE by various groups and countries and also at the mediated versus nonmediated controversy. The reading assignment also included copies of selected transparencies from the lecture and portions of the Midcontinental Regional Medical Library's A Guide to Using MeSH's Alphabetical List and Categorized Lists (Trees). ${ }^{8}$

One unique problem encountered was theft of the MEDLINE terminal. Before it could be replaced the first group of students had finished the MEDLINE unit. They were able to use borrowed equipment for only one evening. The loss pointed up the frustrating dependency of such a course on machines and computer systems. Theft, malfunction of the equipment, system down-time, and similar problems can cripple the progress of the class if alternative plans for instruction are not made in advance.

The restriction of terminal access proved to be another considerable problem. Because of budget limitations and terminal security considerations, the terminal was available to students only the evenings on which the class met. The students needed to have more terminal time in order to understand the system adequately. Since their time was so limited they were very strictly supervised and not really allowed to make their own errors. The restrictions on terminal usage also resulted in the decision not to use MEDLEARN, an on-line instructional package on the use of MEDLINE.

The students' lack of background in health science vocabulary created still another problem. Most of them had little, if any, experience in a health science setting and were thus unaware of the sorts of questions which arise. They handled their assigned search questions fairly well but their lack of background left them floundering when it came to using their free time. They needed quite a bit of supervision in order to make good use of it.

An improvement for the future will be to use the National Library of Medicine's On-line Services Reference Manual $^{9}$ as an assigned reading. Initially it was thought to be too detailed and extensive for such a short and introductory course. By the end of the course, however, it had become evident that at least excerpts from this tool would have been very beneficial to the students despite their limited acquaintance with the system.

Student Evaluation. The students were given the opportunity to evaluate the course near the end of the semester. They were asked to rank various aspects of the course instruction on a one to five scale and also to add any specific or general comments. The amount of narrative response was significant and although there was a natural divergence on various issues, certain repeated points appeared to be valid assessments of the semester's experience. Recurring criticisms were: 


\section{On-Line Bibliographic System Instruction}

1. The class size was unwieldy and should be reduced to maximize hands-on experience for all students.

2. Supplementary readings were somewhat redundant and not appropriate for an introductory level course. They should be deemphasized with more time allotted for on-line experience.

Several suggestions were made about the course organization. A few students felt that each of the three course sections could be included in other existing courses. Others suggested that one of the three sections be dropped so that more time could be devoted to the remaining two. Still others recommended adding a fourth database, e.g., LEXIS, and giving students a choice of three out of four.

With regard to the numerical rankings, the students generally rated the course instructors slightly above average in such areas as organization, enthusiasm, self-confidence, and availability of instructor to students. The rankings were somewhat higher on the instructor's command of the subject and encouragement of participation and class discussion. Across the board the students ranked the over-all value of the course as high and in their comments reiterated the need for continuing this type of course.

Assessments and Alternatives. As has been stated, the course was experimental in structure, format, and content. A few similar courses have been reported in detail, but in all cases the course objectives and resources differed substantially from this effort. ${ }^{10}$ Symptomatic of some of the frustrations of the course were the suggestions that either the enrollment be reduced or the equipment for student use be increased. In the MEDLINE and DIALOG sections, the equipment needed to serve the information needs of library users was just not adequate to meet the needs of this course.

The organization of the course was also an area of concern; probably only the students who wanted a 'splash in the face' were satisfied. Even if one isolated topic from each network had been examined, five weeks would not have been sufficient to provide in-depth treatment. Several students articulated their preference for more - or less - attention to particular systems. Since the close of the semester several alternatives have been considered for the future. Most of these are ones suggested by the students themselves and each creates its own challenges.

One suggestion is to include each of the three types of systems in a traditional course: the OCLC system in a cataloging or academic libraries course; DIALOG in a reference or bibliography course; MEDLINE in a medical librarianship course. This approach would not increase terminal time - would in fact probably decrease it - but would provide an opportunity to explore the relationship of the networks to library services and functions. However, the concept of teaching library networks by comparing different types of databases and system configurations would 
not be supported by burying the networks in separate courses.

Another suggestion is to remove one of the systems from the course, include it in another course and leave two systems to be taught in this one. The extra time could be used for more on-line training. The students who were frustrated with the brief exposure to each system would probably find this more satisfying. The problem here would be deciding which two to retain and which one to remove. Depending on the particular interests of students any one of the three could be dropped.

A further suggestion is to go a step further and add a system, allowing students to choose three out of four. This arrangement would necessitate more elaborate scheduling, especially if the students' choices were not evenly balanced.

The suggestions to reorganize the course and explore other alternatives could be symptomatic of a problem that really cannot be solved by juggling sections. Modifying the course in any one way might satisfy the needs of one group of students but not another. More significantly, the systems chosen for the course are truly disparate. Not only do they have different purposes and operations, but they require different kinds of training to produce various kinds of proficiencies or skills. OCLC terminal operation is largely a mechanical, easily-learned function. The true intellectual effort is in the manipulation of the database for cataloging purposes and in the administration of the system in the library. DIALOG represents just one of several complex (and continually changing) commercially-available retrieval systems, any one of which is difficult to master, and requires also skills in query negotiation and search strategy formulation. The mechanics of MEDLINE are on the surface deceptively simple; proficiency in the use of the system is difficult without extensive training in the use of MeSH and a health science background. The common thread of the units is tenuous and becomes even more so under close scrutiny. Perhaps the incongruity of the networks produces a degree of frustration in adjusting to the three within one semester.

The problems inherent in the structure warrant close monitoring as the course is taught in the future. For the immediate future more terminals will be used and the course will be taught in both the fall and spring semesters in order to fill student demand without increasing size of class. The course as is is definitely filling a curriculum need and the students, while complaining about the details of execution, are generally extremely enthusiastic about the idea for the course. On-line systems themselves are in a state of flux and rapid expansion, with new features, capabilities and subsystems becoming available all the time. From both a curriculum and an instructional viewpoint, what is needed is to keep the over-all goals of the course in mind while maintaining a flexible and adaptable mode of implementation. 


\section{On-Line Bibliographic System Instruction}

\section{References}

1. Harter, S. P.: Instruction Provided by Library Schools in Machine-Readable Bibliographic Data Bases. Proceedings of the ASIS Annual Meeting, 14: 49, 1977, and microfiche in pocket.

2. Kent, A.: Information Science. Journal of Education for Librarianship, 17:131-139, Winter, 1977.

3. Ibid.

4. Bourne, C. P.: DIALOG Lab Workbook; Training Exercises for the Lockheed Information Retrieval Service. Berkeley: Institute of Library Research, University of California, 1976. A Brief Guide to DIALOG Searching, Palo Alto, Calif., Lockheed Information Systems, 1976, was also available to the students.

5. Wax, D. M.: A Handbook for the Introduction of On-line Bibliographic Search Services into Academic Libraries. Office of University Library Management Studies, Occasional Papers, 4, 1976; and Christian, R. W: The Electronic Library: Bibliographic Data Bases 1975-76. White Plains, N.Y., Knowledge Industry Publications, 1975.

6. Juergens, B.: Self-Instructional Introduction to the OCLC Model-100 Terminal. Richardson, Texas, Amigos Bibliographic Council, 1976.

7. Thomas, K. A.: SOLINET Terminal Training Manual. Atlanta, Southeastern Library Network, 1976 , parts 3-4.

8. Midcontinental Regional Medical Library. A Guide to Using MeSH's Alphabetical List and Categorized Lists (Trees). Omaha, Nebraska, Unpublished paper, 1975.

9. National Library of Medicine, Bibliographic Service Division, MEDLARS Management Section. On-line Services Reference Manual. Bethesda, Maryland, 1976.

10. These include: Rees, A.M., Holian, L., and Schaap, A.: An Experiment in Teaching MEDLINE. Bulletin of the Medical Library Association 64:176-202, April, 1976; Sewell, W.: Use of MEDLINE in a Medical Literature Course. Journal of Education for Librarianship 15:35-40, Summer, 1974; and Bourne, C. P., and Anderson, B. E.: Observation on the Use of the Lockheed DIALOG System for Laboratory Work in a Fall 1975 Course on Computer-Based Reference Services at the UCB School of Librarianship. Berkeley: Institute of Library Research, University of California, Unpublished papers, January 1976. A comprehensive summary of the key issues in training can be found in Williams, M. E.: Education and Training for Online Use of Data Bases. (Unpublished paper presented at the EUSIDIC Conference at Graz, Austria, Dec. 1, 1976). 